\title{
19. Soils and their radiometric characteristics
}

\author{
DAVID BEAMish ${ }^{\mathrm{I}}$
}

How to cite this chapter:

Beamish, D., 2016 'Soils and their radiometric characteristics' in M.E. Young (ed.), Unearthed: impacts of the Tellus surveys of the north of Ireland. Dublin. Royal Irish Academy.

DOI:10.3318/ 978-1-908996-88-6.ch19
The Tellus airborne geophysical data sets provide impetus to many new lines of research. The radiometric data, conventionally used for bedrock investigations, have recently been used to support regional mapping of peat extent and thickness, and thus contribute to refining our estimates of the soil carbon inventory. By extending the theory to include density and water saturation we can also begin tentatively to apply these radiometric data to mapping changes in these diagnostic soil characteristics. Here the complete Tellus data set is revisited and examples shown of how radiometric signatures vary over different soil types.

\section{INTRODUCTION: SOILS, SOIL-CARBON AND RADIOMETRIC SURVEYS}

The Tellus airborne gamma-ray spectrometer surveys have mapped the variations in natural terrestrial gamma radiation from soils and rocks across the north of Ireland (Hodgson and Young, Chapter 2, this volume). Radiometric surveys mapping small changes in radioactivity have traditionally been used to support geological mapping and for mineral prospecting. Recent studies have demonstrated their value for environmental purposes, notably for mapping the thickness of peat in Northern Ireland (Beamish, 2013, 2014). Rawlins et al. (2009) used the potassium component of the Tellus radiometric data to improve estimates of soil organic carbon. This chapter provides further examples, from both the Tellus and Tellus Border surveys, of how radiometric data may be applied in support of soil mapping and characterisation.

There is an increasing need to characterise soils and to assess their carbon content. Under the Kyoto Protocol countries are obliged to assess and monitor their carbon 'sinks': natural or artificial reservoirs in which carbon, as a compound with other minerals, may be stored. Soil is a natural sink, in consequence of the organic matter it absorbs, and assessment of soil-carbon stocks is required in establishing the carbon baseline. Research in Ireland contributing to this objective includes work under the STRIVE project (Kiely et al., 2010). For Northern Ireland, relevant inventories of peat and other soils are summarised by the Joint Nature Conservation Committee (2011). Carbon in soil changes over time; dynamic situations where the carbon flux is changing, such as peat bog drainage

${ }^{\mathrm{I}}$ British Geological Survey, Keyworth. 
or restoration projects of Irish blanket and raised bogs through the EU Life programme, require appropriate monitoring. Airborne survey offers a means of rapid regional assessment of such changes. For the most part, soil is derived from underlying bedrock and retains some of its radioactivity. Radiation from the bedrock itself is absorbed or attenuated by overlying soil and peat, particularly if it is saturated. This chapter investigates how these radiometric data have been used to detect differences in certain soil properties and thus indirectly to map spatial variations in soil itself.

\section{THEORY: ATTENUATION OF GAMMA RADIATION BY SOIL}

The naturally occurring total gamma ray flux from the ground is measured by the survey aircraft as a Total Count in counts-per-second (cps). This is a sum of the gamma radiation from all natural and man-made radionuclides within a certain energy range. This flux is reduced or attenuated by various amounts depending on a set of soil properties. The degree of this attenuation and its variability therefore carry information on the soil properties.

When soil is dry the gamma-ray flux is attenuated primarily by the mass of the soil material. Secondary attenuation occurs when the material contains water (Grasty, 1997). The additional attenuation sensitivity of wet soil was investigated by Beamish $(2013,2014)$. The full attenuation response is then controlled by both density and soil wetness. Mineral soils typically display a range of dry densities in excess of $1 \mathrm{~g} \mathrm{~cm}^{-3}$. Organo-mineral soils, being more porous, have densities below this value, with a likely lower limiting value of $0.1 \mathrm{~g} \mathrm{~cm}^{-3}$ in the case of peat. Mineral soils with higher densities typically provide an additional attenuation (say 20\%) only at high moisture levels. Soils with lower densities display increasing additional attenuation sensitivity with decreasing density. In the limiting case of wet peat, attenuation levels increase by $>50 \%$ over their 'dry' equivalents, giving rise to distinctive behaviour. Investigating how radiometric data are attenuated can help in the assessment of soil properties, particularly of joint density-wetness, in the upper $60 \mathrm{~cm}$ of the soil profile.

\section{Radiometric attenuation in the Tellus surveys}

The Total Count (TC) data set for Northern Ireland is shown in Fig. 19.1. Radioactive decay and emissions are statistical and studies of the noise level of the TC data (over deep water bodies where the theoretical flux is zero) indicate a standard deviation of $<40 \mathrm{cps}$. The airborne sensor integrates radiation over a period of 1 s, equivalent to approximately $60 \mathrm{~m}$ along the flight path, and detects signals laterally; consequently the field-of-view is typically in excess of $100 \mathrm{~m}$, which limits resolution.

Gamma-ray attenuation must initially be considered in relation to both the parent material (largely bedrock) and soil information (Beamish, 2013). These data can usefully be supplemented by a wide range of additional near-surface environmental information; for example, vegetation and canopy may hold additional moisture and their potential influences may also be assessed (Beamish, 2015). However, soil property information (e.g. bulk 


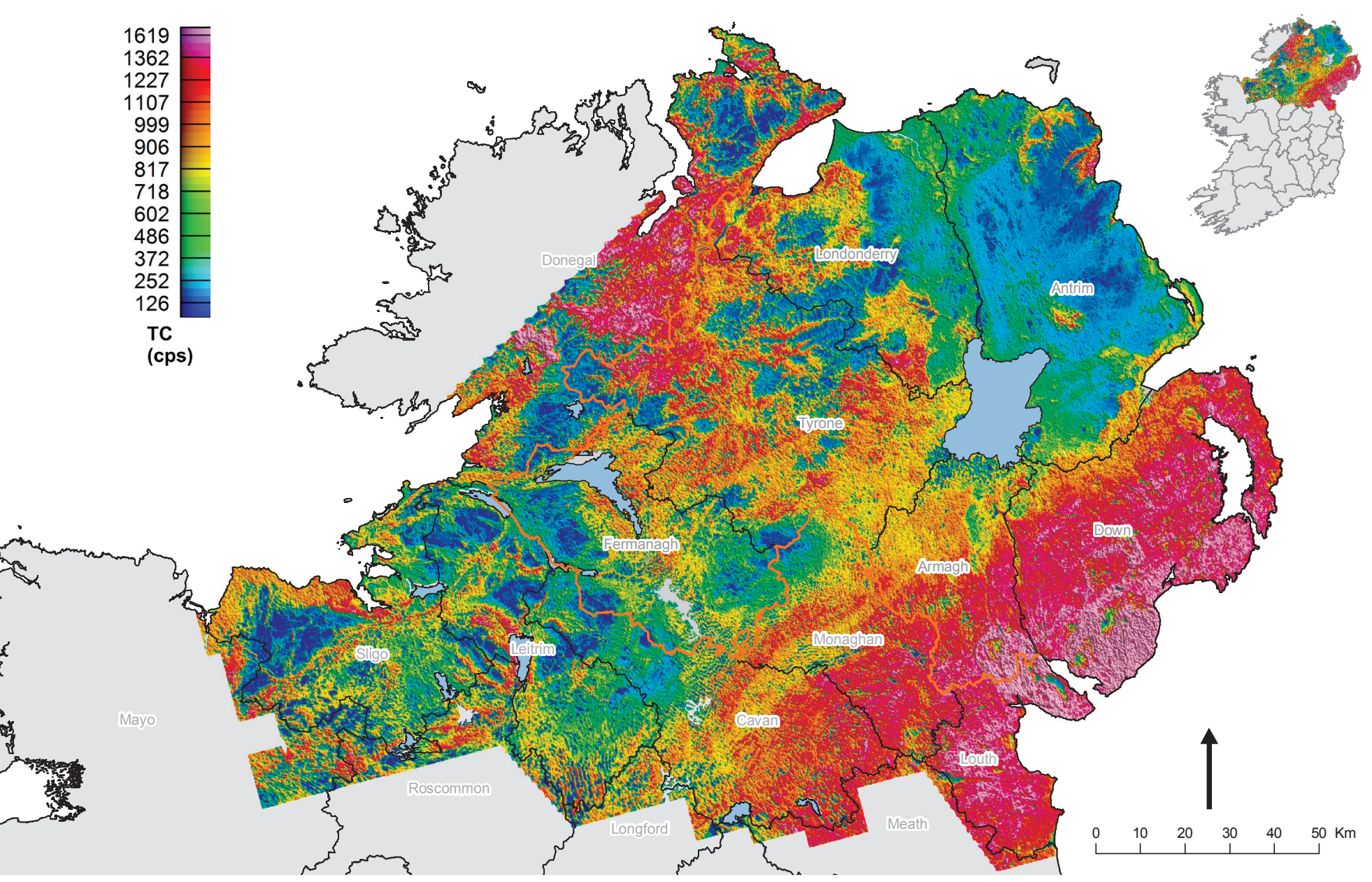

Figure 19.1. Radiometric TC (linear colour scale) of the combined Tellus and Tellus Border data sets. Water bodies $\left(>5 \mathrm{~km}^{2}\right)$ excluded. density and wetness) is unavailable at scales appropriate to the geophysical data. Ideally we require uniform database descriptors of both soil parent material and soil, and here we use the Department of Agriculture and Rural Development (DARD) soil classification (1:250,000 scale) for Northern Ireland (Jordan et al., 2000), as previously described and used by Beamish (2013). For the Republic of Ireland the soils data were obtained from the National Soil Survey (Teagasc, 2006). To further define environmental variability in terms of land classification, CORINE (Coordination of Information on the Environment) databases (1:250,000) are also used (e.g. Cruickshank and Tomlinson, 1996).

\section{Regional variations in radioactivity}

At the scale shown in Fig. 19.1, it is evident that broad divisions in the TC response are controlled by the Southern Uplands - Longford-Down terrane in the south-east, the Antrim basalts in the north-east and by parts of the Grampian terrane in the north-west. Within this framework many local variations are observed and some of these can be accounted for by changes in bedrock lithology, particularly when individual and combined radioelement behaviour is studied. All the studies undertaken to date indicate that the bedrock response accounts for the primary characteristics of the radiometric data. Soil responses are secondary but significant. 


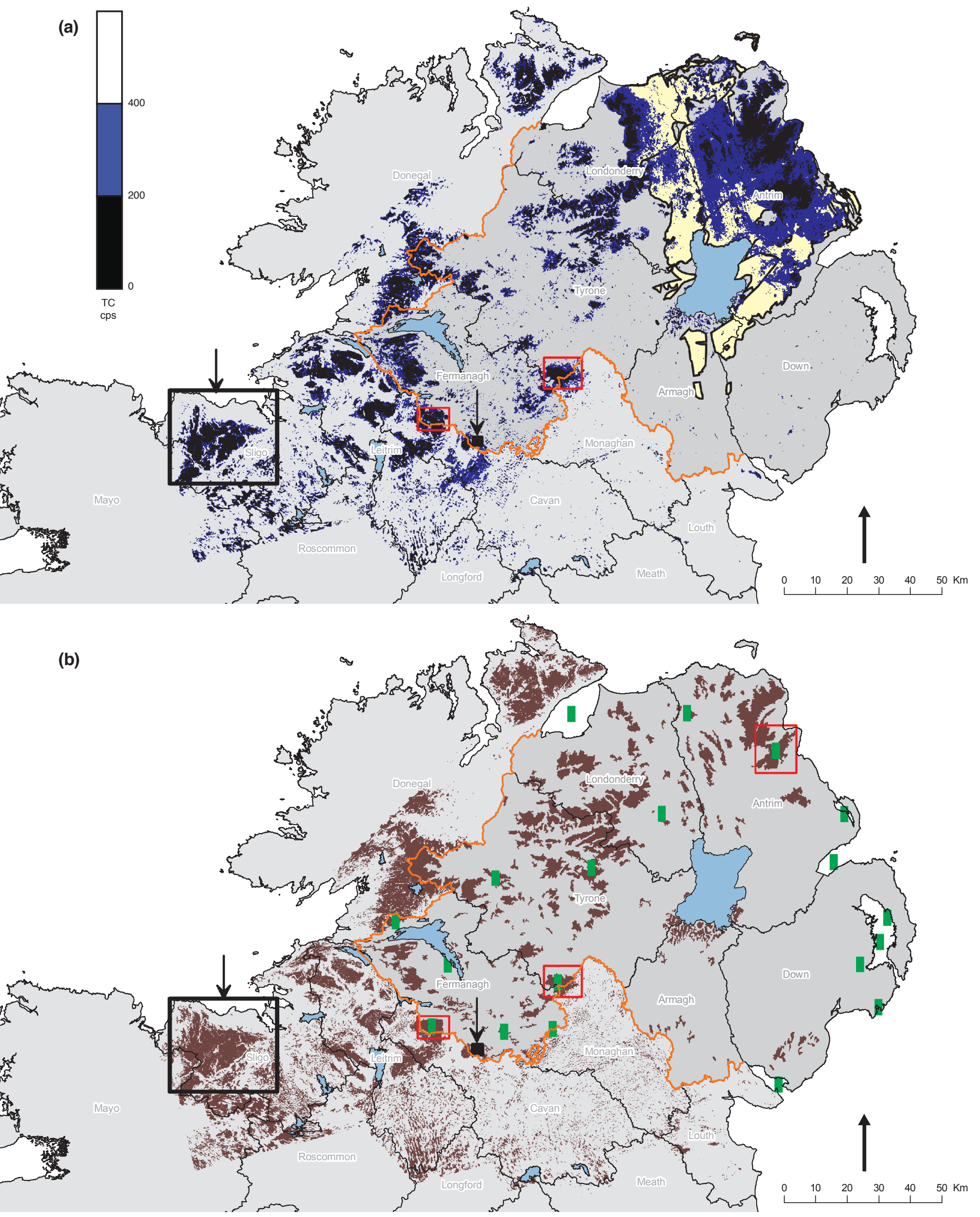


Figure 19.2. (a) Radiometric TC restricted to values of $<400$ cps. Basalt outcrop shown in yellow. (b) Distribution of peat (in brown) from soil databases. Green rectangles are Ramsar wetland sites. Red rectangles denote previous blanket bog studies. Two black rectangles with arrows denote locations discussed here.
The TC data (Fig. 19.1) display a range of low values which are used when assessing attenuation. Figure 19.2a shows the TC data restricted to values of $<400 \mathrm{cps}$, an arbitrary low value threshold. Values below this threshold (black-blue contours) account for about $23 \%$ of the data set. The areas of low response over the Antrim basalts are shown with yellow infill (underlying the attenuation zone) and it is likely that, in part, lithological control within the basalts also influences the data set.

Figure 19.2b shows the extent of peat deposits taken from the soil databases; it is evident that the peat zones (large and small) significantly influence the radiometric response. In the context of bedrock exploration, we observe that $23 \%$ of the Tellus data may have been modified by significant attenuation within organic peat soils. Figure $19.2 \mathrm{~b}$ also shows one of the many environmentally sensitive data sets that are present across the area. The green rectangles denote the high-status Ramsar wetland sites, one of the many environmentally designated areas that could potentially benefit from the Tellus observations. Figure 19.2 also shows three rectangles (in red) containing extensive blanket bog that have previously been studied in relation to their attenuation characteristics. Two black rectangles (arrowed in Fig. 19.2) denote locations considered below.

The Tellus observations also include electromagnetic measurements which assess the electrical conductivity of near-surface materials. The joint use of radiometric and electrical conductivity information to provide a hydrogeological characterisation of protected groundwater-dependent wetlands on Anglesey is described by Beamish and Farr (2013).

\section{Attenuation over a peat bog}

Figure 19.3 shows information assembled across a $29 \times 20 \mathrm{~km}$ area of the Ox Mountains, County Sligo. The bedrock across the area, although complex and containing a major granodiorite intrusion, is not considered to control the attenuation features discussed here. Figure 19.3a shows a base topographic map with shaded relief and the location of the Easky Bog Ramsar site. The area forms the catchment for the river Crowagh and is part of a much larger area of special conservation. Figure 19.3b shows the peat areas from the soil mapping database (blanket bog and cut peat). The TC attenuation ( $<600$ cps) data are shown as contours in Figure 19.3c and zones of TC $<400 \mathrm{cps}$ show a high but partial association with the mapped peat zones. Where bedrock is uniform, the differences may be ascribed to (i) incorrect soil mapping (see Beamish, 2013) and/or (ii) changes in peat properties (the density-wetness combination), due possibly to drainage or peat cutting. Further control is therefore required to take the interpretation further (see Beamish, 2015). The small zones in black identify null responses associated with water bodies where $100 \%$ attenuation occurs. Using these as a reference control, the data interval from 0 to $100 \mathrm{cps}$ is likely to identify zones of soil with the highest water content. The interval from 400 to $600 \mathrm{cps}$, although not necessarily associated with mapped peat soils, also shows soilrelated attenuation clusters. One of the advantages of uniform geophysical coverage is that the data can be further processed by digital methods, and Fig. 19.3d shows an assessment 

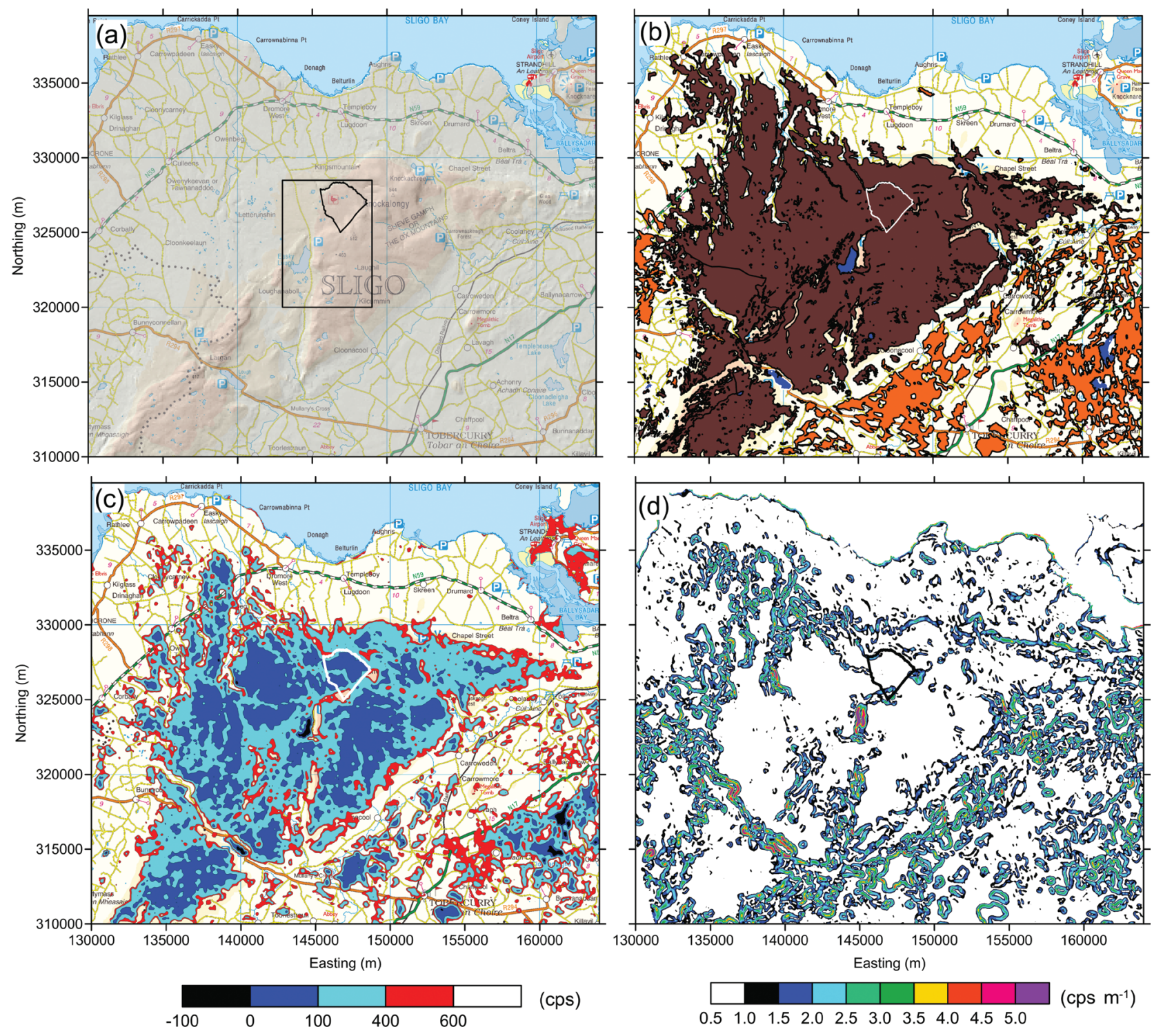

of 'edges' using the horizontal gradient magnitude of the data. The processed data identify the hardest (largest amplitude) edges and provide additional information on locations where soil properties (e.g. the density-wetness combination) change most rapidly.

To demonstrate some of the detail contained in the data we examine more closely the $6 \times$ 8.5 km rectangle shown in Fig. 19.3a. The area includes the Easky Ramsar site, Easky Lough and several dystrophic bog pool systems with intervening quaking lawns. Figure 19.4a shows a $3 \mathrm{D}$ perspective view, looking down on the area from the south-west. The image uses a 20 m digital terrain model (DTM) and includes a 1:250,000 base topographic map with an elevation high of $512 \mathrm{~m}$. Dots show the data sampling locations along the flight lines. The smaller water bodies are too small to be adequately sampled. Figure $19.4 \mathrm{~b}$ shows blanket bog peat zones in brown and water bodies in blue and grey. An absence of peat (in white) occurs on high gradient slopes and along incised water courses. Contours of TC $(<65 \mathrm{cps})$ are overlaid in transparent yellow. The threshold used identifies high attenuation associated with the

Figure 19.3. A $29 \times 20 \mathrm{~km}$ study in the Ox Mountains, Co. Sligo. (a) Topographic base map with hillshade. Rectangle denotes detailed study area of Fig. 19.4. Polygon denotes Easky Ramsar site. (b) Distribution of blanket bog peat (brown) and cut-peat (orange). Water bodies in blue. (c) TC restricted to values of $<600 \mathrm{cps}$. (d) Total horizontal gradient magnitude of TC data. 

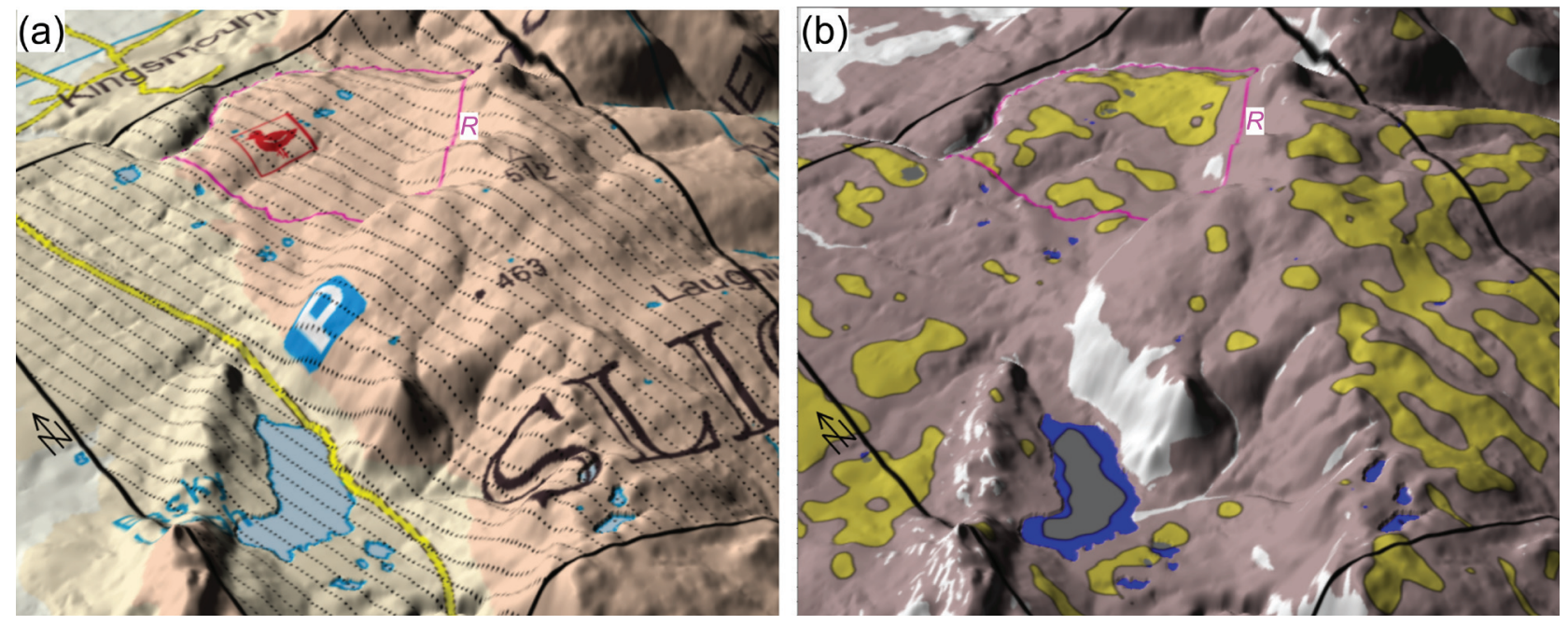

Figure 19.4. (a) 3D perspective view showing part of the $6 \times 8.5 \mathrm{~km}$ rectangle of Fig. 19.3 (black line), the Easky Ramsar site (R), and data points (black dots) draped on a terrain model. (b) Peat areas in brown, non-peat in white. TC restricted to values of $<65$ cps (transparent yellow). Water bodies in blue with main water body in grey. inner area of Easky Lough and many other areas including the Ramsar site. The results imply that the soil properties at the yellow non-Ramsar locations are equivalent to those observed at the Ramsar location. It is also anticipated that the observational variations in soil properties identified have the potential to be incorporated into many other studies of soil mapping (based on texture) and ecological habitats and their conservation.

In order to progress investigations of attenuation in all soil types, a classification of the data according to both soil and parent material (or bedrock) may be carried out (e.g. Beamish, 2013). The result is a spatial convolution of three data sets with the airborne data typically providing the highest spatial resolution (despite their limited field of view). The resulting statistical nature of these classifications/convolutions can be complex. As a consequence, when attenuation studies are performed on the low value tails (which potentially also contain noise) considerable care must be exercised in their interpretation. This is illustrated below.

\section{Attenuation over a non-peat area}

It is evident from Fig. 19.2 that there are many hundreds of localities where attenuation studies could be performed. The following case study of Brown Earth (BE) soils (mature, well-drained mineral soils) is used to indicate some of the interpretational complexities. Figure 19.5a shows a $3 \times 3 \mathrm{~km}$ area (arrowed on Fig. 19.2) with a base topographic map coloured by units of superficial geology. The north-south striking unit (in pink) is glacial sand and gravel outwash (GSG). Several excavation pits are indicated where the resource was exploited. Figure 19.5b shows an image of the TC data and the contacts of the Carboniferous bedrock units (heavy white lines), which comprise a central limestone with argillaceous limestone in the west and mudstone (shale) in the east. The primary largescale TC behaviour derives from the bedrock and high TC values are associated with the two units in the south-west and north-east. The TC response is modified by soil attenuation in certain locations (see below). The TC highs within the central limestone unit are 

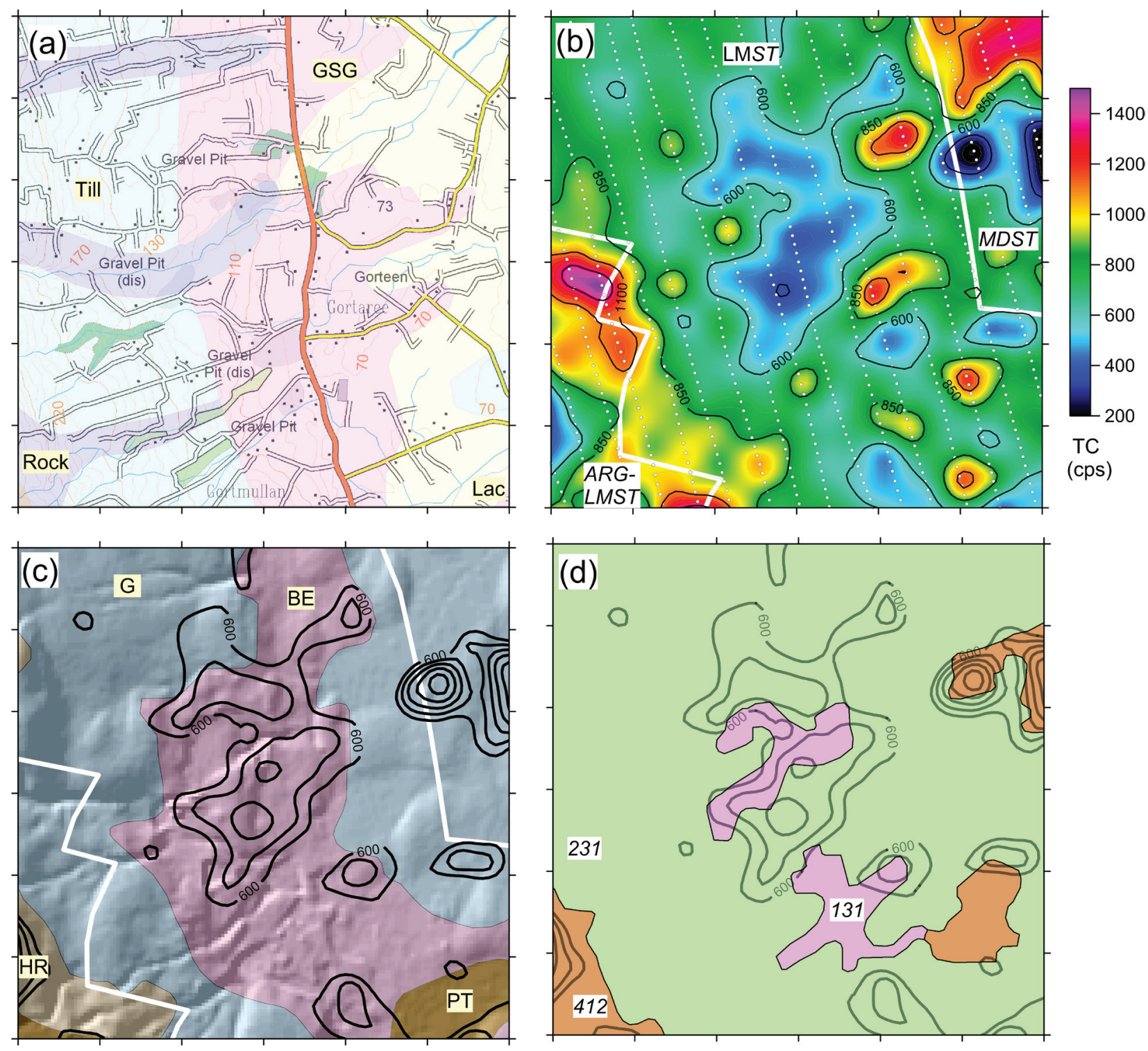

interpreted as changes in lithology (e.g. increased clay) and these data may assist in revising the geological mapping.

The low TC values ( $<600 \mathrm{cps}$ ) are shown in Fig. $19.5 \mathrm{c}$ on a base soil map. The central area comprises a BE soil and this unit appears to be associated with a general trend of low radioactivity values. The major low values in the east appear associated with a Gley $(G)$ soil. By contrast the Peat (PT) unit shown in the south-east corner provides only a minor attenuation response. The attenuation response contours are repeated in Fig. 19.5d on a land-use classification (CORINE) image. Only three codes are present: 131 (pink) is Mineral Extraction Site and Dump, 231 is Pasture and 412 is Peat Bog. The Peat Bog classification shows (in the south-west corner) only a minor correspondence with the PT soil classification shown in Fig. 19.5c. With reference to the two 'new' areas of peat identified in Fig. 19.5d we find that the northernmost unit shows a clear correspondence to the

Figure 19.5. Case study area (see Fig. 19.2 for location). (a) Base topographic map and superficial deposits (GSG = glacial sand and gravel; Lac $=$ lacustrine alluvium). (b) TC data; white dots are data points. Heavy white lines denote bedrock units. (c) Soil data with topographic hillshade $(\mathrm{HR}=$ Humic Ranker, $\mathrm{G}=$ Gley, $\mathrm{BE}=$ Brown Earth, PT = Peat). TC contours $<600 \mathrm{cps}$ in black). (d) CORINE land-use classification (three colours and codes, see text). 


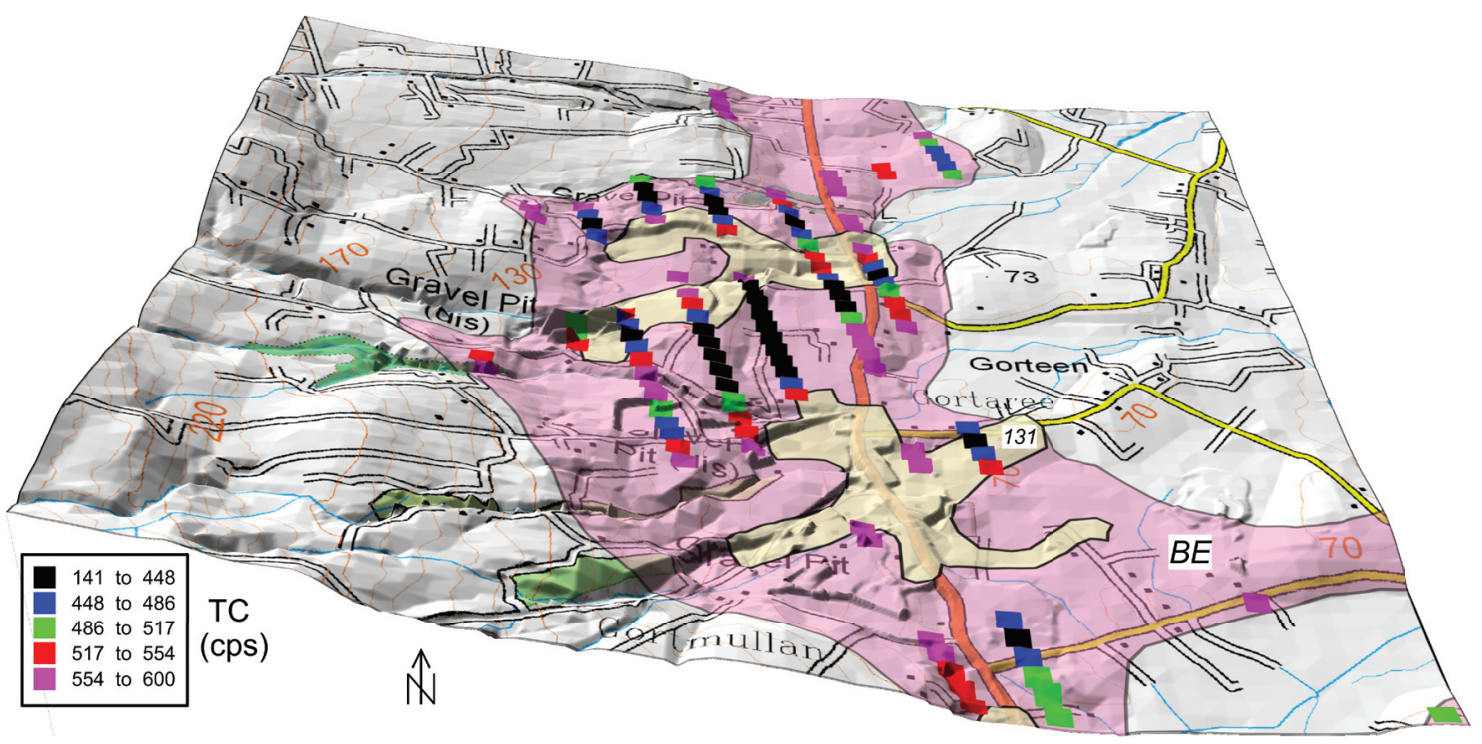

Figure 19.6. 3D perspective view across $3 \times 3 \mathrm{~km}$ rectangle with draped information, looking north. Base topographic map and BE soils (pink) and CORINE class 131 (beige). Lower decile of bedrock classified TC data for BE soils with colour scaling below 600 cps. zone of TC low values across the area. The second area displays only a minor attenuation response from which we conclude: (i) the second area is not a peat soil or (ii) if the zone is peat it has very different properties (density-wetness) with respect to the former unit.

The original objective here was to study attenuation features across the central BE soil unit using a systematic classification approach. Topographic position in the landscape is also important. Figure 19.6 shows a 3D perspective view of the area, looking due north, based on a DTM surface. Additional information includes a base topographic map (Fig. 19.5a), the BE soil unit (Fig. 19.5d) and the CORINE Mineral Extraction polygons (beige). A statistical evaluation of the data (i.e. the complete Tellus data set) classified as BE soils over LMST (limestone) bedrock provides a distribution which is then evaluated. The lowest decile (10\%) of this whole survey distribution provided values of TC $<600$ cps and defines a set of values within this area. These are BE soils which, due to the densitywetness combination, generate high attenuation. The soils have a probability of being wet and therefore 'non-draining'. The low decile 'wet' values are shown, sampled along flight lines, using five colour ranges. It is evident that, across the BE soils, two natural attenuation clusters are observed with limiting low values below $448 \mathrm{cps}$. The two zones largely exclude the areas of sand and gravel workings which are anticipated to provide low water retention. The example demonstrates that the soil profile properties as mapped by airborne survey can offer (i) an insight into misclassification of soil information and (ii) additional information on soil density-wetness not captured by conventional textural mapping.

\section{TOWARDS A WIDER USE OF RADIOMETRIC DATA FOR SOIL AND ENVIRONMENTAL MAPPING}

The studies indicate that quantitative radiometric bedrock exploration can be a valuable additional tool in soil mapping, particularly in mapping variations in physical properties 
that may, on the ground, have been mapped at only a regional scale. Analysis can only be achieved, however, with a fuller understanding of the overlying soil material. Beyond the research into soils and the carbon-store discussed here, we anticipate that the radiometric data can also benefit many environmentally sensitive and ecosystem habitat studies. One mechanism, to overcome intrinsic discipline-based boundaries across the environmental sector, is to make the geophysical data directly available to the appropriate community. One means of achieving this is through the UK Soil Observatory (http://www.ukso.org/), a facility to engage with policy makers, the soil research community, environmental professionals and the public. The many benefits include more transparency and accessibility of data in line with current government data policies and European directives.

\section{ACKNOWLedgements}

This chapter is published with the permission of the Executive Director of the British Geological Survey (NERC).

\section{REFERENCES}

Beamish, D., 2013 'Gamma ray attenuation in the soils of Northern Ireland, with special reference to peat', Journal of Environmental Radioactivity, 115, 13-27. Available at http://nora.nerc.ac.uk/500308/. http://dx.doi.org 10.1016/j.jenvrad.2012.05.031

Beamish, D., 2014 'Peat mapping associations of airborne radiometric survey data', Remote Sensing, 6, 521-39. Available at http://nora.nerc.ac.uk/506700/. http://dx.doi.org 10.3390/rs6010521

Beamish, D., 2015 'Relationships between gamma-ray attenuation and soils in SW England', Geoderma, 259-260, 174-86. Available at http://nora.nerc.ac.uk/511983/. http://dx.doi.org 10.1016/j.geoderma.2015.05.018

Beamish, D. and Farr, G., 2013 'Airborne geophysics: a novel approach to assist hydrogeological investigations at groundwater dependent wetlands', Quarterly Journal of Engineering Geology and Hydrogeology, 46, 53-62. Available at http://nora.nerc.ac.uk/500309/. http://dx.doi.org 10.1144/qjegh2012-019

Cruickshank, M.M. and Tomlinson, R.W., 1996 'Application of CORINE land cover methodology to the UK - some issues raised from northern Ireland', Global Ecology and Biogeography Letters, $5,235-48$.

Grasty, R.L., 1997 'Radon emanation and soil moisture effects on airborne gamma ray measurements', Geophysics, 62, 1379-85.

Joint Nature Conservation Committee, 2011 Towards an Assessment of the State of UK Peatlands. Peterborough, UK. JNCC. Available at http://jncc.defra.gov.uk/pdf/jncc445_web.pdf.

Jordan, C., Higgins, A., Hamill, K. and Cruickshank, J.G., 2000 The Soil Geochemical Atlas of Northern Ireland. Belfast. Department of Agriculture and Rural Development (DARD).

Kiely, G., McGoff, N., Eaton, J., Leahy, P., Xu, X. and Carton, O., 2010 SoilC - measuring and modelling of soil carbon stocks and stock changes in Irish soils, EPA report Strive No. 35. Wexford. Environmental Protection Agency. Available at http://www.epa.ie/pubs/reports/research/land/strive35.html\#.VolwEVLOHYQ.

Rawlins, B.G., Marchant, B.P. Smyth, D. Scheib, C., Lark, R.M. and Jordan, C., 2009 'Airborne radiometric survey data and a DTM as covariates for regional scale mapping of soil organic carbon across Northern Ireland'. European Journal of Soil Science, 60, 1, 44-54. Available at http://nora.nerc.ac.uk/5755/. http://dx.doi.org/10.1111/j.1365-2389.2008.01092.x

Teagasc, 2006. EPA/Teagasc Subsoil Map of Ireland. Dublin. Kinsealy Research Centre. 
Unearthed: impacts of the Tellus surveys of the north of Ireland

First published in 2016 by the

Royal Irish Academy

19 Dawson Street

Dublin 2

www.ria.ie

Copyright (C) 2016 Royal Irish Academy

ISBN: 978-1-908996-88-6

The articles in this book are open access and distributed under the terms of the Creative Commons Attribution 4.0 licence, which permits unrestricted use, distribution and reproduction in any medium, provided the original authors and source are credited. To view a copy of this licence, visit https://creativecommons.org/licenses/by/4.0/

Except where noted:

Geological mapping for Northern Ireland / Tellus data are provided by the Geological Survey of Northern Ireland.

Geological mapping for Ireland / Tellus Border data are provided by the Geological Survey of Ireland.

Topographic mapping for Northern Ireland is derived from Land and Propery Services Open Data and contains public sector information licensed under the Open Government Licence v3.0. (http://www.nationalarchives.gov.uk/doc/open-governmentlicence/version/3/).

Topographic mapping for Ireland is derived from Ordnance Survey of Ireland Open Data (https://creativecommons.org/licenses/by/4.0/legalcode).

While every effort has been made to contact and obtain permission from holders of copyright, if any involuntary infringement of copyright has occurred, sincere apologies are offered, and the owner of such copyright is requested to contact the publisher.

British Library Cataloguing-in-Publication Data. A catalogue record is available from the British Library.

Design: Alex Donald, Geological Survey of Northern Ireland.

Index: Brendan O'Brien.

Printed in Poland by L\&C Printing Group. 


\section{Table of Contents:}

\section{Prelim}

DOI: https://doi.org/10.7486/DRI.b851k323d

\section{Chapter 1}

The Tellus geosciences surveys of the north of Ireland: context, delivery and impacts

DOI: https://doi.org/10.7486/DRI.st74s528d

\section{Chapter 2}

The Tellus airborne geophysical surveys and results DOI: https://doi.org/10.7486/DRI.t148tx96z

\section{Chapter 3}

The Tellus geochemical surveys, results and applications

DOI: https://doi.org/10.7486/DRI.t722wq645

\section{Chapter 4}

Stakeholder engagement for regional geoscientific surveying: the Tellus Border communications campaign

DOI: https://doi.org/10.7486/DRI.w089fr763

\section{Chapter 5}

Mineral resources and Tellus: the essential balance DOI: https://doi.org/10.7486/DRI.wd37kb12s

\section{Chapter 6}

Gold exploration in the north of Ireland: new targets from the Tellus Projects

DOI: https://doi.org/10.7486/DRI.wh24m696v

\section{Chapter 7}

Using soil geochemistry to investigate gold and base metal distribution and dispersal in the glaciated north of Ireland

DOI: https://doi.org/10.7486/DRI.wm11n3806

\section{Chapter 8}

Critical metals for hightechnology applications: mineral exploration potential in the north of Ireland DOI: https://doi.org/10.7486/DRI.wp98p0649

\section{Chapter 9}

A natural laboratory for critical metals investigations in the Mourne Mountains granites

DOI: https://doi.org/10.7486/DRI.cc08ww45f

\section{Chapter 10}

Geothermal potential of granitic rocks of the Mourne Mountains

DOI: https://doi.org/10.7486/DRI.ff36jm09f

\section{Chapter 11}

Shape and intrusion history of the Late Caledonian

Newry Igneous Complex, Northern Ireland

DOI: https://doi.org/10.7486/DRI.2v248822m

\section{Chapter 12}

Using Tellus data to enhance targeting of volcanogenic massive sulphide mineralisation in the Tyrone Igneous Complex

DOI: https://doi.org/10.7486/DRI.5x226w262

\section{Chapter 13}

The geological significance of electrical conductivity anomalies of the Ordovician- Silurian Moffat Shale Group, Northern Ireland

DOI: https://doi.org/10.7486/DRI.6m31f4149

\section{Chapter 14}

Faults, intrusions and flood basalts: the Cenozoic structure of the north of Ireland

DOI: https://doi.org/10.7486/DRI.90205h306

\section{Chapter 15}

Information for agriculture from regional geochemical surveys: the example of soil $\mathrm{pH}$ in the Tellus and Tellus Border data

DOI: https://doi.org/10.7486/DRI.dv14c8060

\section{Chapter 16}

An ecohydrological investigation of wetlands in the border counties of Ireland: a framework for a holistic understanding of wetland systems DOI: https://doi.org/10.7486/DRI.hd775d90j 
Chapter 17

Assessing nutrient enrichment risk to groundwaterdependent ecosystems in the border counties of Ireland DOI: https://doi.org/10.7486/DRI.k356pk18j

\section{Chapter 18}

Mapping the terrestrial gamma radiation dose

DOI: https://doi.org/10.7486/DRI.k930rb86z

\section{Chapter 19}

Soils and their radiometric characteristics

DOI: https://doi.org/10.7486/DRI.mp495t62g

\section{Chapter 20}

Modelling in-house radon potential using Tellus data and geology to supplement inhouse radon measurements

DOI: https://doi.org/10.7486/DRI.ns06hm86z

\section{Chapter 21}

Determining geochemical threshold values from the Tellus data sets: the examples of zinc and iodine| DOI: https://doi.org/10.7486/DRI.r2087418g

\section{Chapter 22}

Identification of the geochemical signatures of diffuse pollution in the Tellus Border soil data set, using source apportionment

DOI: https://doi.org/10.7486/DRI.wh24m698d

\section{Chapter 23}

Stream sediment background concentrations in mineralised catchments in Northern Ireland: assessment of 'pressures' on water bodies in fulfilment of Water Framework Directive objectives DOI: https://doi.org/10.7486/DRI.x633tf86g

\section{Chapter 24}

Mapping metallic contamination of soils in the Lower Foyle catchment

DOI: https://doi.org/10.7486/DRI.9k42bv355

\section{Chapter 25}

Refining the human health risk assessment process in Northern Ireland through the use of oral bioaccessibility data

DOI: https://doi.org/10.7486/DRI.9p29cr199

\section{Chapter 26}

Combining environmental and medical data sets to explore potential associations between environmental factors and health: policy implications for human health risk assessments

DOI: https://doi.org/10.7486/DRI.9s16dn03n

\section{Chapter 27}

Mapping a waste disposal site using Tellus airborne geophysical data

DOI: https://doi.org/10.7486/DRI.9w03fh87q

\section{Chapter 28}

The use of aero-magnetics to enhance a numerical groundwater model of the Lagan Valley aquifer, Northern Ireland

DOI: https://doi.org/10.7486/DRI.9z90gd711

\section{Chapter 29}

Carbon sequestration in the soils of Northern Ireland: potential based on mineralogical controls DOI: https://doi.org/10.7486/DRI.b277h9556

\section{Chapter 30}

Spatial distribution of soil geochemistry in geoforensics DOI: https://doi.org/10.7486/DRI.b564j6392

\section{End matter}

DOI: https://doi.org/10.7486/DRI.bc38m007j 